\title{
As potencialidades sígnicas da fotografia e seus usos na atualidade
}

\section{The signals potentialities of photography and its uses in current}

\author{
1 Luiz Antonio Feliciano luizliu@yahoo.com.br
}

1 Faculdades Integradas Teresa D'Ávila, Universidade estadual de Minas Gerais, Unidade Frutal.

\begin{abstract}
Resumo
Este texto procura problematizar as potencialidades que a fotografia assume, num momento em que a imagem tem permeado grande parte das relações sociais e humanas. Com uma abordagem de caráter teórico-ensaística, o trabalho discute a imagem fotográfica como representatividade sígnica e os seus usos na atualidade. Discorre-se também sobre as possibilidades heurísticas da fotografia, fomentadas pelas suas contextualizações nas rodas de conversa, sobretudo, na escola. Ao se "descascar" uma imagem, intensifica-se sua capacidade de mostrar algumas saídas ou, ainda, apontar novos caminhos para se percorrer. Percursos essenciais para a busca de uma compreensão mais clara do sujeito, do objeto e dos invólucros que os delimitam e os protegem. Espera-se, contudo, que o texto tenha conseguido suscitar esses questionamentos e outros tantos que forem possíveis.
\end{abstract}

\section{Palavras-chave}

Fotografia. Juventude. Escola. Subjetividades. Novas tecnologias.

\begin{abstract}
This text seeks to problematize the potentialities that photography assumes, at a time when the image has permeated much of the social and human relations. With a theoretical-essay approach, the paper discusses the photographic image as a signic representation and its current uses. It also discusses the heuristic possibilities of photography, fostered by their contextualizations on the wheels of conversation, especially at school. By "peeling" an image, it intensifies its ability to show some Outputs, or to point out new avenues to go through. Paths essential for the search for a clearer understanding of the subject, the object and the envelopes that delimit and protect them. It is hoped, however, that the text has succeeded in raising these questions and as many others as possible.
\end{abstract}

\section{Keywords}

Photography. Youth. School. Subjectivities. New technologies.

\section{Como você deve citar?}

FELICIANO, Luiz Antonio. As potencialidades sígnicas da fotografia e seus usos na atualidade. Cadernos UniFOA, Volta Redonda, n. 36, p. 47-54, abr. 2018. 


\section{INTRODUÇÃO}

Se pararmos para pensar, talvez não consigamos imaginar o ser humano constituído de toda sua roupagem cultural, sem uma forma de linguagem que possibilite sua construção como sujeita e sua vivência na alteridade. "É na linguagem, e por meio dela, que construímos a leitura da vida e da nossa própria história". (SOUZA, 2008, p. 21).

Se dedicarmos um tempo, mínimo que seja, para vislumbrar tal questionamento, esbarrará sempre numa valorização excessiva em uma das maneiras mais peculiares de comunicação que conhecemos: a escrita, isso em detrimento a tantas outras maneiras - fala, gestos, expressões, desenhos, pinturas, gráficos, imagens estáticas e em movimento, etc - , inerentes ao nosso convívio em sociedade e por acreditar que é na alfabetização que se encontra a intelectualidade que esse juízo de valor acontece. A alegria dos pais em ver e ouvir o primeiro "papai, mamãe", quase grunhido, da criança é facilmente superada pelos primeiros rabiscos, nas folhas do caderno, nos primeiros dias da escola. A fala que o acompanhou desde o primeiro ano de idade e tornou possível esse encontro do lápis com o papel perde sua importância diante do novo aprendizado. Nessas atitudes, já se inserem a função de toda forma de linguagem: carregar sentidos.

O que difere o homem dos outros animais é a sua capacidade de significar. É na produção simbólica que o homem garante sua hegemonia sobre todos os outros seres. Nesse sentido, quando o pai ou a mãe veem no aprendizado da escrita, pelo filho, um valor social diferente, o sentido de status quo é, então, inserido naquela atitude. Aquele simples ato de escrever carrega um discurso, produzido anteriormente por outras Vozes, que diferencia a pessoa alfabetizada da não alfabetizada. Entretanto, esses sentidos nem sempre são tão claros. As falas do homem do campo que chamava de Doutor os filhos dos fazendeiros que saiam para estudar, independente do curso que faziam, é um exemplo desses sentidos embutidos nos discursos. Tanto que, até hoje, ainda se tratam os advogados, os engenheiros e os médicos como doutores, mesmo diversos deles não tendo defendido tese alguma em um programa de doutoramento.

Mas o que torna possível essa capacidade das coisas em carregar sentido? A habilidade do homem em colocar significados em todas as suas experiências. É como sujeito da história que ele encontra essa aptidão de significar as coisas. Todo acontecimento é único e só pode ser (re)vivenciado, se houver a sua posse. Visto por esse ângulo, toda forma de linguagem é uma maneira de aprisionamento das experiências. 0 signo, como componente indispensável de toda e qualquer possibilidade de linguagem, carrega consigo esse fardo de aprisionar experiências. Os significados só podem existir mediante as experiências vividas. Bakhtin (2006) reforça essa ideia quando diz que,

\footnotetext{
na realidade, não são palavras o que pronunciamos ou escutamos, mas verdades ou mentiras, coisas boas ou más, importantes ou triviais, agradáveis ou desagradáveis, etc. A palavra está sempre carregada de um conteúdo ou de um sentido ideológico ou vivencial. É assim que compreendemos as palavras e somente reagimos àquelas que despertam em nós ressonâncias ideológicas ou concernentes à vida. (2006, p. 81. Grifo do autor).
}

Não conseguimos buscar o sentido de determinado signo (ou palavra) se ele não está diretamente envolvido com as nossas experiências. 0 signo cumpre a função de transportar o significado para onde quer que vá. Mas essa função é arbitrária, está a serviço do poder. Como diz Barthes, "a língua, como desempenho de toda linguagem, não é nem reacionária, nem progressista; ela é simplesmente: fascista; pois o fascismo não é impedir de dizer, é obrigar a dizer." (BARTHES, 1996: p. 13). Aí reside a arbitrariedade do signo. Se é arbitrário, é ideológico. Se é ideológico, quer transportar para o Outro o sentido que se encontra nesse signo. Por estar a serviço da linguagem, tem a função de suscitar mudanças naquele que o recebe. Quando se fala da linguagem falada ou escrita, parte-se do princípio de um código pré-definido. No entanto, quando analisamos outras formas de comunicação, entramos em um campo em que a arbitrariedade não é tão evidente. 
Nesse sentido, busca-se, no presente trabalho, discutir um signo, presente na cotidianidade social hodierna, que não apresenta um código tão definido como o da linguagem escrita ou falada: o signo imagético; ou, ainda, mais especificamente, a fotografia. Pela sua analogia ao objeto representado, ela camufla toda intencionalidade de seu produtor. A imersão da sociedade contemporânea no universo das imagens, sobretudo a fotografia, reforça a necessidade dos estudos cada vez mais intensos sobre essa temática. É difícil pensar a sociedade em que se vive atualmente sem olhar para os dispositivos que a constitui. Dessa forma, esse texto quer dar sua contribuição para problematizações concernentes ao universo da fotografia e seus usos na contemporaneidade. Sem a intenção de esgotar todas as possibilidades, tarefa impossível para qualquer ciência, propõe-se apenas alguns insights em torno da fotografia e sua capacidade sígnica.

\subsection{A fotografia como signo}

Vivemos inseridos num universo carregado de imagens por todos os lados. Desde o acordar até o último piscar dos olhos, no final da noite, é inúmera a quantidade de imagens que intermedia o nosso cotidiano. Não nos damos conta da infinidade de imagens que figuram diante de nós. Como ultrapassar esse pântano sem se deixar afundar em seus espaços movediços?

Como vimos, o signo carrega em si uma ideologia inerente ao seu constituir-se. A imagem fotográfica, assim como todas as outras formas de signos, participa dessa constituição ideológica. Se acreditamos no signo como uma concentração de experiências, e, portanto, ideológico, a fotografia se insere, da mesma maneira, como um espaço que agrupa as ideologias de quem as produz. É nesse contexto que Machado afirma que

os sistemas simbólicos que os homens constroem para representar o mundo são ideológicos exatamente porque, longe de constituírem entidades autônomas transparentes, estão sendo determinados, em última instância, pelas contradições da vida social. (MACHADO, 1984, p. 13. Grifos do autor.).

Partindo desse contexto, a fotografia carrega toda a ideologia do fotógrafo (profissional ou amador) que a produz. Ela possui a capacidade de representar ou, ainda, de reter uma experiência própria do autor. No entanto, uma experiência carregada das outras experiências que ajudaram o fotógrafo a constituir-se como sujeito. Portanto, a fotografia, além de reflexo da realidade representada, dado a sua possibilidade físico/química, é, da mesma maneira ou num grau ainda maior, uma refração dessa mesma realidade. Machado auxilia, ainda, quando diz que

[...] ao representar, ao construir sistemas para operacionalizar o mundo, ao articular relações em que se acha
mergulhado, o homem necessariamente "inverte", isto é, interfere, interpreta e altera o objeto representado, porque
a ação do sujeito é sempre produtiva e não pode ser reduzida à atitude do espectador passivo. Se a atividade
representativa - a atividade ideológica - é "inversora", os critérios dessa inversão estão dados pela estratégia
operativa de cada grupo, gangue, clã, casta, raça ou, na sociedade de classes, por cada uma das classes que se
enfrentam na arena social. (MACHADO, 1984, p. 14. Grifos do autor).

É nesse sentido que o signo, seja ele verbal ou figurativo, refrata uma realidade. A fotografia cumpre esse papel de oferecer uma realidade recriada pelo fotógrafo, pois é em si apenas um instrumento a serviço daquele que a usa. A realidade que ela apresenta não é idêntica a que representa, dadas todas as escolhas pertinentes ao fotógrafo no ato do clique: enquadramento, ângulo de tomada, cenário, lente, diafragma, velocidade de obturador, etc., todas essas preferências dependem da ideologia de quem "tira" a fotografia. Cada ato fotográfico, por mais involuntário que seja, é único e carregado de um sentido próprio, porém, composto pelos diversos discursos que ajudaram a construir o autor como sujeito. 


\subsection{Usos contemporâneos da fotografia}

Vimos que a fotografia é carregada de sentido e é envolvida por discursos de outrem. Mas como pensar a sociedade atual sem essa prática que se prolifera a cada dia? Não é difícil perceber que a fotografia já faz parte do cotidiano dessa geração digital. Fotografa-se tudo e a todo instante. Das flores no jardim às mesas do café, dos encontros com os amigos aos quartos solitários, em dias de sol e em dias de chuva. Se estiver triste, fotografa, se estiver feliz, mais ainda. As novas tecnologias tornaram viável uma prática potencial nas pessoas: fotografar. As máquinas digitais - e, mais ainda, os celulares - facilitaram o manuseio do equipamento e baratearam os custos de produção. A internet possibilitou a publicação e a recepção dessas imagens. A instantaneidade, característica das sociedades contemporâneas, oferecida por esses aparelhos tecnológicos, foi recebida de braços abertos pelo público que não via a hora disso acontecer. A fotografia digital iniciou um novo modus operandi na relação com a imagem.

Nos primeiros tempos da fotografia, a necessidade de se (re)tratar esbarrava-se em um custo alto e uma dificuldade de deslocamento até os estúdios dos fotógrafos. Momentos da vida que precisavam ser eternizados, como os rituais religiosos de passagem (batizado, $1^{\text {a }}$ eucaristia, casamento), eram construídos, em mise-en-scène, para que o registro pudesse ser feito, uma característica documental da fotografia herdada da pintura. Com o avanço tecnológico, as câmeras diminuíram de tamanho e os filmes em rolo foram criados, permitindo ao fotógrafo uma autonomia maior, o que o possibilitou registrar os acontecimentos in loco. No início do século passado, o olhar mercadológico de George Eastman, fundador da Kodak, facilitou a proliferação da prática fotográfica pelo mundo todo. No entanto, foi em meados da década de 70 que a fotografia se torna popular no Brasil. Até então, as classes populares ainda dependiam dos estúdios fotográficos para garantir o registro, mesmo simulado, de qualquer situação que merecesse um registro. Com a chegada das câmeras automáticas, a fotografia ganha um fôlego maior e começa a se difundir entre as classes populares. A partir daí, não só os rituais religiosos de passagem ganham um registro imagético, mas os momentos de quebra do cotidiano passam a se eternizar através da fotografia. As viagens, as reuniões familiares, os encontros dos amigos, todos os momentos que se desprendem das atividades cotidianas começam a ser registrado pelas câmeras compactas.

A partir do final dos anos 90, com a chegada da câmera digital, os momentos a serem fotografados se ampliam. $\mathrm{O}$ acesso à nova tecnologia pelos jovens dá um novo rumo ao valor representativo dos momentos que precisam ser fotografados. Se antes os rituais de passagem religiosos estavam à frente da lista de importância, hoje, eles disputam lugar com os acontecimentos cotidianos. Se esses rituais pontuavam ciclos importantes da vida, hoje, as vivências do dia a dia constroem um ciclo quase único. A fotografia digital vem inaugurar esse novo estágio sobre a vida. As mínimas coisas do dia a dia ganham um valor inestimável para serem fotografadas, como se, num estalar dos dedos, redescobríssemos o nosso envolto. Mas a cotidianidade é efêmera como a própria fotografia digital sugere. Fotografar e deletar são atividades consonantes. 0 cotidiano é tão fugaz como a própria fotografia que o pretende eternizar. Pais, ao abordar o cotidiano, aponta que

o quotidiano - costuma dizer-se - é o que se passa todos os dias. Mas também se costuma dizer que no quotidiano nada se passa que fuja a ordem da rotina e da monotonia. Então o quotidiano seria o que no dia-a-dia se passa quando nada se parece passar. Mas só interrogando as modalidades através das quais se passa o quotidiano - modalidades que caracterizam ou representam a vida passante do quotidiano - nos damos conta de que é nos aspectos frívolos e anódinos da vida social, no "nada de novo" do quotidiano, que encontramos condições e possibilidades de resistência que alimentam a sua própria rotura. (PAIS, 1993: p. 108.) 
Mas o que abriu nossos olhos? 0 que permitiu que as coisas simples tomassem tanta importância para nós? Outra tecnologia que aparece de mãos dadas com as novas máquinas de imagem: a internet. Esse espaço de relações sociais, diferente de todos os outros, não permite uma participação passiva. Seu diferencial é a interatividade. Não há como adentrar nesse universo e ficar vendo as coisas acontecerem, é necessário contribuir para que ele aconteça. Os sites de relacionamento (facebook, instagram, twitter, youtube, entre outros) ${ }^{2}$ e todas as possibilidades que a rede oferece, existem pela novidade e imediatismo que apresentam. Se só o que é novo e imediato ganha audiência, só serei visto se apresento coisas novas todos os dias. Mas como suprir com novidades, se os momentos socialmente eleitos não acontecem todos os dias? Resta, então, buscar esses elementos onde a vida realmente acontece: no cotidiano. É lá que o percurso da vida se dá com todas as nuances possíveis. Isso ganha valor ritual que merece ser mostrado. A instantaneidade da fotografia digital não poderia vir em melhor hora. Pode-se fotografar e publicar (postar) ao mesmo tempo. Os conteúdos podem ser renovados a todo instante para não se perder a atenção de ninguém.

Se, por um lado, a rapidez entre fazer o clique e ver o resultado possibilitou a inserção de novos conteúdos a todo instante na internet, por outro lado, trouxe uma nova maneira de se relacionar com a imagem. Se, outrora, a inquietação e a ansiedade em ver as fotos the garantiam um valor de posse de uma realidade fugidia, atualmente, a instantaneidade lhe garante um valor de efemeridade. Antes as fotografias garantiam uma (re)visitação ao momento fotografado, hoje se deleta com a mesma rapidez com que se fotografa. E o sentido de posse só aparece juntamente com o sentido de perda, quando se formata o computador e todas as imagens são perdidas. Aí, instaura-se um sentimento de pânico, como se houvesse uma amnésia total, como se todas as memórias fossem apagadas juntas com o deletar. De toda forma, independente dos usos e das práticas sociais que a fotografia possibilita e dos suportes utilizados para seu registro, é importante dizer que ela ainda se vale pelo seu reflexo, muito mais que pela sua refração. E, acima de tudo, ainda se acredita que ela lhe rouba a alma.

\title{
1.3 Do olhar descompromissado à curiosidade epistemológica
}

\begin{abstract}
Sempre tive uma paixão pela pintura. Quando criança, eu pintava às quintas e domingos, e nos outros dias sonhava com isto. Como muitas CRIANÇAS, eu tinha a minha câmara Brownie, mas só a usava de tempos em tempos para preencher pequenos álbuns com lembranças de férias. Foi só muito mais tarde que comecei a olhar melhor através do aparelho; meu pequeno mundo se ampliava, e este foi o fim das fotografias de férias. (CARTIER-BRESSON, 2004: p. 15. Grifo nosso.)
\end{abstract}

Diante de todas as mudanças ocorridas na relação com a fotografia, não há como negar: se fotografa-se mais, a possibilidade de se conhecer as coisas é também maior. Se a fotografia é mais refratária que reflexiva, ela permite uma descoberta dos sentidos impostos a ela pelo grupo social que a utiliza. Mas como servir de descoberta, se ela mesma nos confina num reflexo da realidade o que é refratário? Só através de uma curiosidade que se transforma em epistemologia tira-se proveito máximo desse suporte. Quando uma pessoa - adolescente, jovem, adulto, idoso - empunha sua câmera digital ou mesmo seu celular e dispara diante de seu cotidiano, uma série de escolhas são pré-definidas de acordo com a utilização a que vai se prestar tal imagem. Mesmo que essas escolhas não estejam diretamente ligadas às operacionalidades técnicas do equipamento, os objetivos buscados já carregam de sentido suas seleções. Produzir imagens para abastecer o Instagram ou o Facebook, a priori, parece uma atitude desprovida de intencionalidade. No entanto, é uma maneira de reproduzir uma ordem, institucionalizada pela comunidade virtual, de estar sempre atualizado para não cair no esquecimento.

2 O site marketing de conteúdo apresenta uma lista das 10 redes sociais online mais utilizados no Brasil. https://marketingdeconteudo.com/redes-sociais-mais-usadas-no-brasil/. Acesso em: 10 abr. 2018, às 09h29min 
A tecnologia chega independente da nossa vontade. Urge a necessidade de uma atenção maior as todas as possibilidades que ela oferece. Fazer com que o jovem pense sobre suas ações não é algo tão inovador, todavia, torna-se cada vez mais necessário. A escola é, sobretudo, o espaço mais contundente para uma reflexão sobre as próprias atitudes. É lá que as relações de alteridade acontecem num grau e teor mais elevados. Nesse espaço, o aluno adquire, nos horários de aula, o conhecimento institucionalizado, que o qualifica diante da sociedade. Já, nos intervalos, é numa arena social que ele tem a possibilidade de narrar suas histórias e, da mesma forma, ouvir as narrativas dos Outros. O convívio com o diferente possibilita o confronto de ideias, importante na formação do sujeito. As experiências trazidas por cada um são encharcadas de vivacidade e contribuem na construção deles como sujeitos. Nessa troca de informações, os alunos se afetam mutuamente e produzem, com isso, aprendizagens múltiplas (DAYRELL, 2007).

\begin{abstract}
O cotidiano escolar torna-se um espaço complexo de interações, com demarcação de identidades e estilos, visíveis na formação dos mais diferentes grupos, que nem sempre coincidem com aqueles que os jovens formam fora dela. A escola aparece como um espaço aberto a uma vida não-escolar, numa comunidade juvenil de reconhecimento interpessoal. É em torno dessa sociabilidade que muitas vezes a escola e seu espaço físico são apropriados pelos jovens alunos e reelaborados, ganhando novos sentidos. (DAYRELL, 2007: p. 1120.)
\end{abstract}

Alguns desses jovens experimentam sua condição juvenil em outros espaços e procuram preservar essas práticas e modos de vida consolidados. Outros não conseguem diferentes experimentações fora do espaço escolar, procurando, assim, fazê-lo dentro da escola (SPOSITO, 2005). A vivência entre pares facilita essas descobertas.

Contudo, nessa arena social, onde as ideologias, as vivências, as narrativas se encontram e se defrontam, a fotografia, hoje, aparece como um elemento propulsor de discussões. Os celulares, pela potencialidade híbrida, carregam arquivadas as últimas imagens feitas dos momentos vivenciados. E não é raro encontrar os jovens em verdadeiras sessões para rever e relembrar as histórias vividas no final de semana ou no dia anterior ou mesmo as que acabaram de ser feitas no próprio grupo. $\mathrm{E}$ por que não trazer esse ritual para dentro da sala de aula? Ou, então, levar a sala de aula para essas arenas? Aí reside a potencialidade da fotografia como instrumento educativo. Ela já propicia uma troca de experiências entre os adolescentes nos espaços físicos e virtuais, restando, agora, utilizar-se desse potencial e suscitar discussões epistemológicas. Paulo Freire (1996, p. 99.) aponta para essa necessidade do educador, quando "adverte da necessária promoção da curiosidade espontânea para a curiosidade epistemológica". Mas o que vem a ser esse estado de mudança? Cabe ao educador instigar o educando a buscar respostas para suas curiosidades. É nesse movimento que o conhecimento vai se constituindo de forma diferente para as necessidades de cada um. Não como um receituário, mas de forma natural, pois a curiosidade é inerente ao ser humano.

\title{
2 CONSIDERAÇÕES FINAIS
}

Nos seus quase duzentos anos de existência, a fotografia foi ganhando seu espaço junto à sociedade de forma cada vez mais contundente. Com apelos mercadológicos mais insistentes e uma necessidade maior de visibilidade em meio ao oceano de imagens, em que a contemporaneidade obriga as pessoas, sobretudo, os jovens, encontram na tecnologia sua grande aliada. Os novos dispositivos produtores de imagens, a facilidade do acesso à internet para qualquer publicação e a disponibilidade para a interação, através das redes sociais, possibilitaram reconfigurações nos modos de vivência em sociedade. Ninguém está livre de ser atingido por essas transformações. Em maior ou menor grau, as pessoas acabam sendo influenciadas pelas mudanças que a dinamicidade da vida em comunidade potencializa. 
Nesse sentido, olhar para a sociedade é procurar abarcar, em um mesmo contexto, as subjetividades que se entrelaçam e as tecnologias que as envolvem. Nesse caso, procurou-se abordar, de forma sucinta, a fotografia no seu envolto sígnico e na sua potencialidade construtiva de novos conhecimentos tanto da sociedade como das suas relações. Por esse viés, a exemplificação do jovem no seu cotidiano escolar aponta a força que os dispositivos tecnológicos ganham na construção das subjetividades. Nesse universo, a fotografia recebe diferentes significações dadas às diversas leituras que ela se permite. A fina camada que envolve a imagem não pode tornar-se uma delimitação impenetrável a ponto de carregar as verdades absolutas. A fotografia, dada as suas condições de feitura, é uma mentira. Porém, o importante é saber como o fotógrafo se vale dessa mentira para falar as suas verdades (FONTCUBERTA, 2002). Desse modo, percebe-se a necessidade de aprofundar-se na leitura da imagem para não se perder em tábuas rasas. Para Bateson (1986), o contexto é que possibilita o significado. Essa contextualização é que potencializa o descascar da fotografia.

A fotografia como representação sígnica carece de problematizações contextualizadas que desenvolvam discussões em torno da potencialização da sua usabilidade e, ainda, do seu papel como interface das relações sociais e humanas. Pelo envolvimento do jovem com a tecnologia e o tempo dedicado à escolarização, torna-se importante também abordagens sobre a função preponderante da imagem e da tecnologia na construção subjetiva juvenil. Essas investigações tornam-se necessárias pela atualidade da temática e pela necessidade de se pensar relações humanas saudáveis e envolventes. Espera-se que este trabalho possa propulsionar outras discussões ainda mais consistentes. 


\section{REFERÊNCIAS}

BAKHTIN, Mikhail. Marxismo e filosofia da linguagem. 12. ed. São Paulo: Ed. Hucitec, 2006.

BARTHES, Roland. Aula. PERRONE-MOISÉS, Leyla (Trad.). São Paulo: Ed. Cultrix, 1996.

BATESON, Gregory. Mente e natureza: a unidade necessária. GERPE, Claudia (trad.). Rio de Janeiro: Ed. Francisco Alves, 1986.

CARTIER-BRESSON, Henri. O instante decisivo. In. 0 imaginário segundo a natureza. AGUIAR, Renato (Trad.). Portugal: Editorial Gustavo Gili, 2004.

DAYRELL. Juarez. A escola "faz" as juventudes? Reflexões em torno da socialização juvenil. In: Educ. Soc., Campinas, vol. 28, n. 100 - Especial, p. 1105-1128, out. 2007.

FONTCUBERTA, Joan. El beso de Judas: Fotografía y verdade. 4. ed. Barcelona: Editorial Gustavo Gili SA, 2002.

FREIRE, Paulo. Pedagogia da autonomia: saberes necessários à prática educativa. São Paulo: Ed. Terra e Paz, 1997.

MACHADO, Arlindo. A llusão Especular. Introdução à Fotografia. Rio de Janeiro: Ed. Brasiliense, Funarte, 1984.

PAIS, José Machado. Nas rotas do quotidiano. In: Revista Crítica de Ciências Sociais, nº 37, s. L., junho/1993, p. 105-113.

SPOSITO, Marilia Pontes. Indagações sobre as relações entre juventude e a escola no Brasil: Institucionalização tradicional e novos significados. In: JOVENes, Revista de Estudios sobre Juventud. México, DF, ano 9, núm. 22, p. 201-227, jan.-jun. 2005.

SOUZA, Solange J. e. Infância e linguagem: Bakhtin, Vygotsky e Benjamin. 11. ed. São Paulo: Papirus, 2008. 